\title{
Verzeichnis der untersuchten deutschsprachigen Operetten
}

Adieu Mimi
Die Bajadere
Eine Ballnacht
Der Bettelstudent
Die blaue Mazur
Die Blume von Hawaii
Boccaccio
Bruder Straubinger
Brüderlein Fein
Casanova
Cloclo
Die Csárdásfürstin
Die Dollarprinzessin
Das Dorf ohne Glocke
Das Dreimäderlhaus
Die Faschingsfee
Fatinitza
Der fidele Bauer
Die Fledermaus
Frasquita
Frau Luna
Friederike
Das Fürstenkind
Gasparone
Die geschiedene Frau
Giuditta
Die gold'ne Meisterin
Der Graf von Luxemburg
Gräfin Mariza
Ein Herbstmanöver
Die Herzogin von Chicago
Das Hollandweibchen
Die Juxheirat
Die Kaiserin
Lady Hamilton
Das Land des Lächelns
Der letzte Walzer
Der liebe Augustin

\author{
Die lustige Witwe \\ Die lustigen Nibelungen \\ Madame Pompadour \\ Mädi \\ Majestät Mimi \\ Der Mann mit den drei Frauen \\ Eine Nacht in Venedig \\ Der Opernball \\ Der Orlow \\ Paganini \\ Prinzeß Gretl \\ Der Rastelbinder \\ Die Rose von Stambul \\ Rund um die Liebe \\ Die schöne Galathée \\ Schützenliesl \\ Schwarzwaldmädel \\ Die spanische Nachtigall \\ Der süße Kavalier \\ Die süßen Grisetten \\ Die Tanzgräfin \\ Der tapfere Soldat \\ Der Tenor der Herzogin \\ Der unsterbliche Lump \\ Das Veilchen vom Montmartre \\ DerVetter aus Dingsda \\ Viktoria und ihr Husar \\ DerVogelhändler \\ Ein Walzertraum \\ Im weißen Rössl \\ Wiener Blut \\ Wiener Frauen \\ Das Wirtshaus im Spessart \\ Der Zarewitsch \\ Der Zigeunerbaron \\ Zigeunerliebe \\ Der Zigeunerprimas \\ Die Zirkusprinzessin
}

